\title{
A Comparison of Health Status in Patients with Chronic diabetic foot ulcerations and Minor foot amputations
}

\section{Comparación del Estado de Salud en Pacientes con Úlceras Crónicas y Amputaciones Menores en el Pie}

\author{
Formosa $C^{1}$, Simiana $C^{1}$, Gatt $A^{1}$. \\ 1. Departament of Podiatry, University of Malta, Malta. \\ ${ }^{*}$ Correspondence: Cynthia Formosa (Senior Lecturer). Faculty of Health Sciences. University of Malta. Email: cynthia.formosa@um.edu.mt
}

\section{Abstract}

Objective: The aim of this study was to get a better understanding of the general health status between people living with either a chronic foot ulceration or minor foot amputation.

Methods: A non-experimental prospective design study was conducted on 39 subjects living with Type-2 diabetes; 17 patients with ulceration for at least 3 months and 22 patients with a digital or transmetatarsal amputation for at least 6 months. The Short-form 36 version 2 was used to evaluate health status in the study group.

Results: A significant difference was found between patients living with chronic foot ulceration or minor foot amputations ( $p=0.006$ ) with subjects with a minor amputation reporting a better general health status. Further statistical analysis comparing the eight scales of the SF36 v2 identified four significant health domains including Physical Functioning $[p=0.021]$, Role Physical $[p=0.002], V i t a l i t y$ [ $p=0.011]$ and Role emotional $[p=0.015]$ between the ulceration group and the toe- or- transmetatarsal- amputation group.

Conclusion: Diabetic foot ulcerations remain a major concern for patients, healthcare givers and family members. This study has concluded that patients with foot ulcerations have decreased health status including physical, emotional and social function. Better strategies for the prevention of diabetic foot ulcerations including better clinical decision making regarding treatment, early intervention and prompt referral to the multidisciplinary diabetic foot team is warranted. Cultural issues should also be considered to ensure appropriate care.

\section{Key Words: Diabetes, Health status, Amputation, Ulceration.}

\section{Resumen}

Objetivos: El objetivo de el estudio era conocer el estado de salud en personas que presentan una ulcera crónica en el pie o una amputación menor en el pie.

Metodo: Un estudio prospectivo no experimental se llevó a cabo en 39 sujetos con diabetes tipo $2 ; 17$ pacientes con ulceración durante al menos 3 meses y 22 pacientes con una amputación digital o transmetatarsiana durante al menos 6 meses. La versión 36 corta 2 se utilizó para evaluar el estado de salud en los grupos del estudio.

Resultados: Se encontró una diferencia significativa entre los pacientes que presentan ulceración crónica del pie o amputaciones menores del pie $(p=0,006)$ con un mejor estado de salud general que el grupo que presentan amputaciones menores. Además el análisis estadístico comparando las ocho escalas de los cuatro dominios importantes para la salud SF-36 v2 identificados incluyendo funcionamiento físico [p = $0,021]$, rol físico [ $p=0,002]$, Vitalidad $[p=0,011]$ y rol emocional $[p=0,015]$ entre el grupo ulceración y amputación.

Conclusión: Las ulceraciones del pie diabético sigue siendo una preocupación importante para los pacientes, los cuidadores y miembros de la familia. Este estudio concluye que los pacientes con úlceras en el pie han disminuido el estado de salud incluyendo la función física, emocional y social. Mejores estrategias para la prevención de las úlceras del pie diabético, incluyen una mejor toma de decisiones clínicas en relación con el tratamiento, la intervención temprana y la pronta remisión al equipo multidisciplinar del pie diabético. Las cuestiones culturales también deben ser consideradas para asegurar la atención adecuada.

\section{Palabras Clave: Diabetes, Estado de salud, Amputación, Ulceración.}

Received: 03 April 2016; Acept: 05 May 2016.

Conflicts of Interest

The authors declare no potential conflicts of interest with respect to the research, authorship, and/or publication of this article.

Funding

The authors received no financial support for the research, authorship, and/or publication of this article. 


\section{Introduction}

The incidence of diabetes is increasing worldwide and an estimated $4-10 \%$ of people with type 2 diabetes develop foot ulceration (1). This is of concern for both people with diabetes and healthcare providers, with episodes of ulceration strongly associated with lower-extremity amputations, reduced quality of life, long periods of hospitalization and substantial health care costs (2).The scope of the problem of the diabetic foot is big and this is highlighted by the fact that it has been reported that every 30 seconds a leg is amputated somewhere around the world (3).

Diabetic foot ulcerations can take weeks or months to heal and can sometimes not heal at all (4). Owing to poor healing results, many patients will need to be admitted to hospital for inpatient treatment (5). Non-healing ulcerations can result in local infection, gangrene and amputation of the limb (6). Diabetic foot ulcerations and amputations are amongst the most common complications of diabetes mellitus (7). Various studies $(8,9)$ have shown that foot ulcerations and amputations result in a detrimental effect on the patient's health status and quality of life, which affects their physical, social and emotional status.

The cornerstone of this approach to the diabetic foot is to encourage early presentation to allow early diagnosis and early intervention within the multidisciplinary diabetic foot team (3). This emphasizes the importance of ensuring continuous research in order to identify the best methods of management to ensure high quality and effective treatment in the high risk foot (10).

Ten percent of the Maltese population has diabetes, compared with $2-5 \%$ of the population in its neighbouring European countries.
Expectably, foot ulceration, and ulcer recurrence, is common in the Maltese population with diabetes. The higher incidence of type 2 diabetes and its complications in Malta, when compared with broadly similar surrounding populations, suggests the contribution of uniquely Maltese traditions and cultural habits to the pathophysiology of this condition. This has prompted the authors to conduct this study in a population with a diverse culture.

\section{Material and Methods}

A non-experimental prospective study was conducted. Participants were recruited from a local diabetes foot clinic. Individuals were recruited from the Diabetes Podiatry Clinic, Mater Dei Hospital, Malta (the only public hospital in Malta). An average of 5,000 people attend the Diabetes Podiatry Clinic annually, with approximately 500 experiencing ulceration.

Informed consent was obtained from all individual participants included in the study. Thirty nine participants both males and females were interviewed. Participants eligible for this study were Maltese, aged $>45$ years with type 2 diabetes and primarily responsible for their own care. This study was approved by the University Research Ethics Committee and all participants provided informed consent before any data collection. All procedures performed in studies involving human participants were in accordance with the ethical standards of the institutional and/or national research committee and with the 1964 Helsinki declaration and its later amendments or comparable ethical standards.

Consenting participants attending the local Diabetes Podiatry Clinic with the diagnosis of type 2 diabetes and living with either a chronic ulcer for at least 3 months or with a healed minor foot amputations including digital or transmetatarsal amputations for at least 6 months were included in this study. Subjects who did not give informed consent and those who could not communicate were excluded from this study. 
Thirty-nine participants were conveniently selected on a "first through the door" basis; 17 patients with ulceration and 22 patients with a healed digital or transmetatarsal amputation. All those meeting the inclusion criteria $(n=39)$ were invited verbally and in writing to participate in the study.

\section{Outcome measure}

The outcome variable measured for both groups was health status. Health status was assessed by means of the the SF-36 V2. The SF-36 v2 measures eight scales which are grouped into two general health areas (11), including also some degree of psychological standards. The Physical Health area includes the Physical Functioning scale (10 items), Role-Physical scale (4 items), Bodily Pain scale (2 items) and General Health scale (5 items). In addition, Mental Health areas include Vitality (4 items), Social Functioning scale (2 items), Role-Emotional (3 items) and Mental Health (5 items). The QaulityMetric Health Outcomes ${ }^{\mathrm{TM}}$ Scoring software 4.5 was used to score the eight health dimensions of the SF-36 v2. Results obtained were on a scale of 0 to 100 , where zero indicates the worst possible health status and 100 indicates the best health status. The data were analysed using Statistical Package for Social Sciences (SPSS) version 18. Normality of distribution was established using a Kolmogorov Smirnov test. The Independent-Sample t-test was used to compare the mean General Health Status between the two independent groups.

\section{Study Protocol}

Upon consent patients were interviewed once during the study. Interviews were conducted in a quiet room. The patients were interviewed using the SF-36 v2 questionnaire. Each interview was coded with an identification number to ensure anonymity.
Results

The SF- 36 version 2 was used to evaluate the health status. Table 1 illustrates the mean scores of General Health Status between groups. A significant difference was found between patients living with chronic foot ulceration and a healed minor foot amputations $(\mathrm{p}=0.006)$ with subjects with a healed minor amputation reporting a better general health status.

Table 1 Independent Sample t-Test for General Health Status

\begin{tabular}{lccc}
\hline Group & Sample Size & $\begin{array}{c}\text { Health Status } \\
\text { Scores Mean }\end{array}$ & P-value \\
\hline $\begin{array}{l}\text { General Health Status } \\
\text { Amputations }\end{array}$ & 22 & 49.62 & $\mathbf{0 . 0 0 6}^{*}$ \\
Ulcers & 17 & 42.82 & \\
\hline
\end{tabular}

*Representing Statistical Difference between groups

Further statistical analysis comparing the eight scales of the SF-36 v2 identified four significant health domains including Physical Functioning $[\mathrm{p}=0.021]$, Role Physical $[\mathrm{p}=0.002]$, Vitality $[\mathrm{p}=$ $0.011]$ and Role emotional $[p=0.015]$ between the ulceration group and the toe- or- transmetatarsalamputation group as illustrated in Table 2.

Table 2 Independent Sample t-Test for the eight scales of the SF-36 v 2 within study group.

\begin{tabular}{llccc}
\hline & \multicolumn{1}{c}{ Group } & $\begin{array}{c}\text { Sample } \\
\text { Size }\end{array}$ & Mean & $\begin{array}{c}\text { P- } \\
\text { value }\end{array}$ \\
\hline Physical Functioning & Amputations & 22 & 47.5377 & $\mathbf{0 . 0 2 1} *$ \\
& Ulcers & 17 & 40.6553 & \\
Role Physical & Amputations & 22 & 48.8877 & $\mathbf{0 . 0 0 2 *}$ \\
& Ulcers & 17 & 38.1353 & \\
Bodily Pain & Amputations & 22 & 52.7977 & 0.079 \\
& Ulcers & 17 & 45.6100 & \\
General Health & Amputations & 22 & 43.7409 & 0.487 \\
& Ulcers & 17 & 41.7471 & \\
Vitality & Amputations & 22 & 56.2445 & $\mathbf{0 . 0 1 1} *$ \\
& Ulcers & 17 & 47.8818 & \\
Social Functioning & Amputations & 22 & 50.7323 & 0.078 \\
\multirow{2}{*}{ Role Emotional } & Ulcers & 17 & 45.2488 & \\
& Amputations & 22 & 46.8305 & $\mathbf{0 . 0 1 5}$ \\
Mental Health & Ulcers & 17 & 37.9406 & \\
& Amputations & 22 & 50.1550 & 0.148 \\
\hline & Ulcers & 17 & 45.3282 & \\
\hline
\end{tabular}

*Representing Statistical Difference between groups 


\section{Discussion}

The aim of this study was to get a better understanding of the general health status between people living with either a diabetic chronic foot ulceration or healed minor foot amputation in a specific population with a specific culture. This is the first pilot study in a Maltese cohort. This study has highlighted a significant difference in health status between the two groups in this specific population, with participants living with a healed digital or transmetatarsal amputation for at least 6 months exhibiting a better health status when compared to patients who were still living with ulceration. Furthermore, participants who had undergone minor amputations but healed successfully reported better physical Functioning, role Physical, vitality and role emotional that participants with current ulcerations. Similar studies have also reported similar results (12).

This finding stimulates discourse with regards to the poor quality of life which people living ulcerations endure during their course of disease even when compared to patients who have undergone minor amputations but whose amputation healed successfully. The literature suggests that diabetes complications including foot ulcerations could be ameliorated and even prevented if this condition is managed correctly.

The culture and history of Malta has significantly contributed to the higher than average incidence and prevalence of diabetes. Hereditary features, ethnicity, cultural family traditions and lifestyle factors all contribute in the development of disease. Successful management of diabetes and its complications requires an understanding of the history, religion, culture and family and social networks of the people concerned. Diabetes complications cannot be addressed only from the medical aspects of chronic disease but should encompass psychosocial and cultural factors as well. This will undoubtedly go a long way towards alleviating, to some extent, the costs and burden regarding the management of diabetes complications in Malta.
When diabetes care is organized properly and is culturally appropriate, most diabetic foot ulcerations are known to resolve (3) since the key to successful management has been reported to be a triad of early presentation, early diagnosis and early treatment. Further to this, the authors of this paper suggest that the health status of these individuals needs to be evaluated periodically as part of this treatment plan. This could directly establish a more patient-centred care. This can be achieved by addressing both the physical health and the mental health and cultural issues and thus treatments can be tailored according to the needs of the individual with a higher chance of treatment endurance by the individual which will in turn result in improved care and outcomes. To achieve this, a multidisciplinary team approach is required to be able to address the biopsychosocial model of care.

This model prompted a revolution in medical thinking by providing an argument and rationale that better links medicine to science, however the literature reports a great concern with regards to this team approach since in many countries this is not yet available (3). All diabetic foot ulcerations should be referred to the multidisciplinary team without delay so that the opportunity of healing is not wasted. Radical change in any healthcare system is required to fully realize the benefits of team working. Challenges to the implementation of multidisciplinary care require institutional commitment and support. Health care cultures that include group affiliation, teamwork and good coordination have been associated with greater implementation of continuous quality improvement practices and higher functional health status, when compared to organisational cultures that emphasise formal structures, regulations and poor relationships between stakeholders (13). 


\section{Limitations of Study}

Although conducted in a diverse population with a diverse culture and the limited sample size $(\mathrm{N}=39)$ restricts the possibility to draw conclusions from the results to the general diabetes population, the study findings reinforce the findings of similar studies conducted in other populations (12). For this reason this study could be considered a pilot study with the authors' recommending repeating this study with a larger sample size. Furthermore a power analysis should be calculated to ensure the recruitment of the correct sample size. Future studies could also take into account certain variables such as systemic malignancies, age, gender and relate these to the result of Health Status of patients. Furthermore comparison of health status with other groups of patients such as patients living with diabetes without foot ulceration and patients with chronic diabetic foot ulceration healed at 6 months or more.

\section{Conclusions}

Diabetic foot ulcerations remain a major concern for both patients', healthcare givers and family members. This study has concluded that patients with foot ulcerations have decreased health status including physical, emotional and social function. Better strategies for the prevention of diabetic foot ulcerations including better clinical decision making regarding treatment, early intervention and prompt referral to the multidisciplinary diabetic foot team is warranted. 


\section{References}

1. Lauterbach S, Kostev K, Kohlmann T. Prevalence of diabetic foot syndrome and its risk factors in the UK. J Wound Care 2010; 333-7.

2. Boulton A, Vileikyte L, Ragnarson-Tennvall G, Apelqvist J. The global burden of diabetic foot disease. The Lancet 2005; 1719-1724.

3. Edmonds ME, Foster AVM, Sanders LJ: 'Diabetic Foot Care" $2^{\text {nd }}$ Edition, Blackwell Publishing, Inc., UK, 2008.

4. Frykberg R. Diabetic foot ulcers: Pathogenesis and management. American Family Physician 2002; 66.

5. Vuerstaek J D, Vainas T, Wuite J, Nelemans P, Neumann MH, \& Veraart J C. State-of-the-art treatment of chronic leg ulcers: a randomized controlled trial comparing vacuumassisted closure (VAC) with modern wound dressings. Journal of Vascular Surgery 2006; 44(5): 1029-1037.

6. Lavery L A, LaFontaine J D, Higgins K, Lanctot D R, \& Constantinides G. Shear-Reducing Insoles to Prevent Foot Ulceration in High-Risk Diabetic Patients. Advances in Skin and Wound Care 2012; 519-524.

7. Valensi P, Girod I, Baron F, et al. Quality of life and clinical correlates in patients with diabetic foot ulcers. Diabetes Metab 2005; 31(3 Pt 1):263-271.

8. Goodridge D, Trepman E, Sloan J, et al. Quality of life of adults with unhealed and healed diabetic foot ulcers. Foot and Ankle International 2006; 27(4): 274-280.

9. Vileikyte L. Diabetic foot ulcers: a quality of life issue. Diabetes Metabolism Research and Reviews 2001, 17(4): 246-249.

10. Wu S C, Marston W, Armstrong D G. Wound Care - The Role of Advanced Wound-healing Technologies. JAPMA 2010; 385-394.

11. Rabin R, de Charro F. EQ-5D: a measure of health stuatus from the EuroQol group. Health-related quality of life in clinical studies 2001; 33(5): 337-343.

12. Winkley K, Stahl D, Chalder T, et al. Quality of life in people with their first diabetic foot ulcer: a prospective cohort study. JAPMA 99(5): 406-414, 2009.

13. Formosa C, Mandy A, Lucas K. Identifying Changes in Dabetes Care. Practical Diabetes International 2011; 28(1): 31-34. 